\title{
Role of capsid proteins in parvoviruses infection
}

\author{
Mengyu $\mathrm{Tu}^{1 \dagger}$, Fei Liu ${ }^{3+}$, Shun Chen ${ }^{1,2,3^{*}}$, Mingshu Wang ${ }^{1,2,3}$ and Anchun Cheng ${ }^{1,2,3^{*}}$
}

\begin{abstract}
The parvoviruses are widely spread in many species and are among the smallest DNA animal viruses. The parvovirus is composed of a single strand molecule of DNA wrapped into an icosahedral capsid. In a viral infection, the massy capsid participates in the entire viral infection process, which is summarized in this review. The capsid protein VP1 is primarily responsible for the infectivity of the virus, and the nuclear localization signal (NLS) of the VP1 serves as a guide to assist the viral genome in locating the nucleus. The dominant protein VP2 provides an "anti-receptor", which interacts with the cellular receptor and leads to the further internalization of virus, and, the N-terminal of VP2 also cooperates with the VP1 to prompt the process of nucleus translocation. Additionally, a cleavage protein VP3 is a part of the capsid, which exists only in several members of the parvovirus family; however, the function of this cleavage protein remains to be fully determined. Parvoviruses can suffer from the extreme environmental conditions such as low $\mathrm{pH}$, or even escape from the recognition of pattern recognition receptors (PRRs), due to the protection of the stable capsid, which is thought to be an immune escape mechanism. The applications of the capsid proteins to the screening and the treatment of diseases are also discussed. The processes of viral infection should be noted, because understanding the virus-host interactions will contribute to the development of therapeutic vaccines.
\end{abstract}

Keywords: Parvovirus, capsid proteins, functions, viral infection

\section{Background}

Parvoviruses infect a wide range of species, including birds and mammals. The virus replicates in the nucleus, although some of the parvoviruses require a helper virus to replicate $[1$, 2]. The viral replication must occur in mitotic cells because the virus must use a polymerase to effectively proliferate. Based on the host specificity, the Parvoviridae family is divided into two groups, the Parvovirinae and the Densovirinae. Parvovirinae infects vertebrates, whereas Densovirinae infects only invertebrates. Recently, a new classification of the Parvoviridae family was proposed, and the latest subfamily designation, the Parvovirinae, now has eight genera: Amdoparvovirus, Aveparvovirus, Bocaparvovirus, Copiparvovirus, Dependoparvovirus, Erythroparvovirus, Protoparvovirus and Tetraparvovirus [3]. The human parvovirus B19 (B19) causes a serious autoimmune disease in children [4]. An infection with the virus during pregnancy can lead to hydrops foetalis and foetal loss or congenital infection [5]. The adeno-associated viruses

\footnotetext{
*Correspondence: sophia_cs@163.com; chenganchun@vip.163.com

${ }^{\dagger}$ Equal contributors

'Institute of Preventive Veterinary Medicine, Sichuan Agricultural University,

Wenjiang District, Chengdu City, Sichuan Province 611130, China

Full list of author information is available at the end of the article
}

(AAVs) are nonpathogenic and replication-defective viruses in the Parvoviridae family, with twelve distinct AAV serotypes and more than 100 recombinant species [6]. Additionally, the AAVs cannot effectively complete replication without the help of viruses such as adenoviruses or herpesviruses [2]. In animals, the most common symptoms are gastroenteritis and diarrhoea [7-9]. In general, parvoviruses agglutinate erythrocytes, but the goose parvovirus (GPV) is an exception; the GPV cannot agglutinate red blood cells but agglutinates cattle sperm [8].

Because of the specific immunogenicity, capsid proteins have great potential for the development of vaccines. The baculovirus expression system has been widely used to produce virus-like particles (VLPs), which share a immunogenicity that is similar to native viruses and that can be applied to further study of the functional aspects $[10,11]$. Generally, the VLPs are well immunogens which can induce a strong and specific antiviral immune response. Although the analyses of the structural and functional aspects of the VLPs have always attracted much attention, there is no systematic description of the function of each capsid protein during the viral invasion. 
In this paper, the genome and the encoding proteins of parvoviruses and the roles of capsid proteins of the viruses in viral infection are summarized, leading to suggestions for possible mechanisms to explain the interactions between virus and host. Moreover, we reviewed the application of recombinant viral capsids to the treatment of diseases.

\section{The genome and encoding proteins of parvoviruses}

The parvovirus genomes are approximately $5.0 \mathrm{~kb}$ in length and is enclosed within an icosahedron capsid $(\mathrm{T}=1)$, which is $18-26 \mathrm{~nm}$ in diameter. At both ends of the genome, inverted terminal repeats (ITR) are formed by palindromic sequences, which are assembled into different shapes of a hairpin structure (depending on virus). In most of the parvoviruses, the viral DNA encodes two open reading frames (ORF). The ORF1 encodes nonstructural proteins (NS), and the ORF2 encodes two or three viral particle (VP) proteins which assemble the viral capsid; the VP proteins share a common termination codon. However, a few parvoviruses possess more than two ORFs, including, for example, members of the Bocaparvovirus, which have an extra ORF that encodes a nuclear phosphoprotein NP1 [12-15]. The NS protein is a replicate protein that control genomic replication, is cytotoxic to host cells and is a cause of apoptosis [16, 17]. Successful examples of continuously producing viral particles in cell lines did not occur until a lac repressoroperator system was included, which first successfully overcame the cytotoxicity problem and allowed for stringent regulation of these proteins [18]. The NS1 protein has several replication-related regions, for example, a DNA-binding region, an ATP binding region, a helicase domain and a transactivation domain [16]. In the B19, $\mathrm{AAV}$, minute virus of mice (MVM), canine parvovirus $(\mathrm{CPV})$, porcine parvovirus (PPV), bovine parvovirus (BPV) and GPV, the VP1 contains the entire sequence of the VP2. Compared with the VP2, the VP1 has an extra length of $\sim 140$ amino acids at the N-terminal, with a phospholipase $\mathrm{A}_{2}\left(\mathrm{PLA}_{2}\right)$ domain and an NLS. The VP2 constitutes the primary component of the capsid protein and is highly conserved. The VP3 is a cleavage product that appears after the translation of VP2, and not all the parvoviruses have this protein. Although sequence diversity exists among the different species, these viruses have similar structures as determined by the three-dimensional structures, such as for B19 [19], AAV [20-27], MVM [28], CPV [29, 30], BPV [9] and the Aleutian mink disease virus (ADV) [31].

\section{Role of parvovirus capsid in viral infection}

The multifunctional capsid is responsible for the adsorption on and the entrance into the host cell, intracellular transport and localization, viral egress and induction of the immune response. Figure 1 shows the process of viral infection. In the following sections, the function of each capsid protein during the viral infection will be discussed.

\section{VP1 is responsible for viral infectivity}

In most parvoviruses, the VP1 N-terminal changes location from internal to being external of the capsid when exposed to some extreme chemical and physical conditions, such as heat or low $\mathrm{pH}$. Moreover, the heat-induced exposure of the VP1 N-terminal is an irreversible process $[32,33]$. The conformational changes of the capsid VP1 and the exposure of the VP1 N-terminal play a considerable role in viral infection. In previous studies with B19, a recombinant capsid VP1 N-terminal with a unique region (VP1u) was readily recognized by a specific monoclonal antibody, whereas the natural capsid was not recognized. Furthermore, after a heat or a low-pH treatment, the native VP1u was accessible to the antibody [34]. These results revealed a primarily conformational difference between the native and recombinant virion for VP1u and preliminarily showed that the B19 VP1u peptides were originally located inside the capsid. Additionally, the CPV and MVM virions exposed the VP1 N-terminal during endosomal trafficking, which also argued that the VP1 Nterminal was initially hidden in the viral capsid [33, 35]. Mutational experiments confirmed that the VP1 Nterminal of the MVM directly affected the infectivity of the virus [36]. Additionally, the direct effect the VP1 Nterminal on infectivity was observed with AAV-2. The microinjection of wild-type AAV-2 directly into the cytoplasm resulted in low infectivity, but the infectivity improved with the exposure of the VP1 N-terminal, which strongly suggested again that the VP1 N-termini are essential for the intracellular virion to initiate infection [37]. Additional studies revealed that B19 VP1u became external after primary cellular receptor attachment [38, 39]. Furthermore, the VP1u mediated internalization was a highly restricted process and only occurred in the permissive erythroid lineages, which suggested a viral tropism and pathogenesis [40].

The NLS is a nuclear localization signal that assists in the navigation of viruses to the nucleus, which leads to further nuclear translocation. A previous study identified a typical NLS on the VP1 N-terminal residues 4-13 in the $\mathrm{CPV}$ and demonstrated that the nuclear translocation was an ATP-dependent process [41]. An NLS was also identified in the MVM [36]. Moreover, the VP1 Nterminal region of the MVM is composed of four basic amino acid clusters, BC1, BC2, BC3 and BC4. Mutational and biochemical studies determined that $\mathrm{BC} 1$ and $\mathrm{BC} 2$ exhibited a great potential for nuclear transport [36]. The sequences of the $\mathrm{BCs}$ are highly conserved among parvoviruses; thus, we inferred that the $\mathrm{BC}$ 


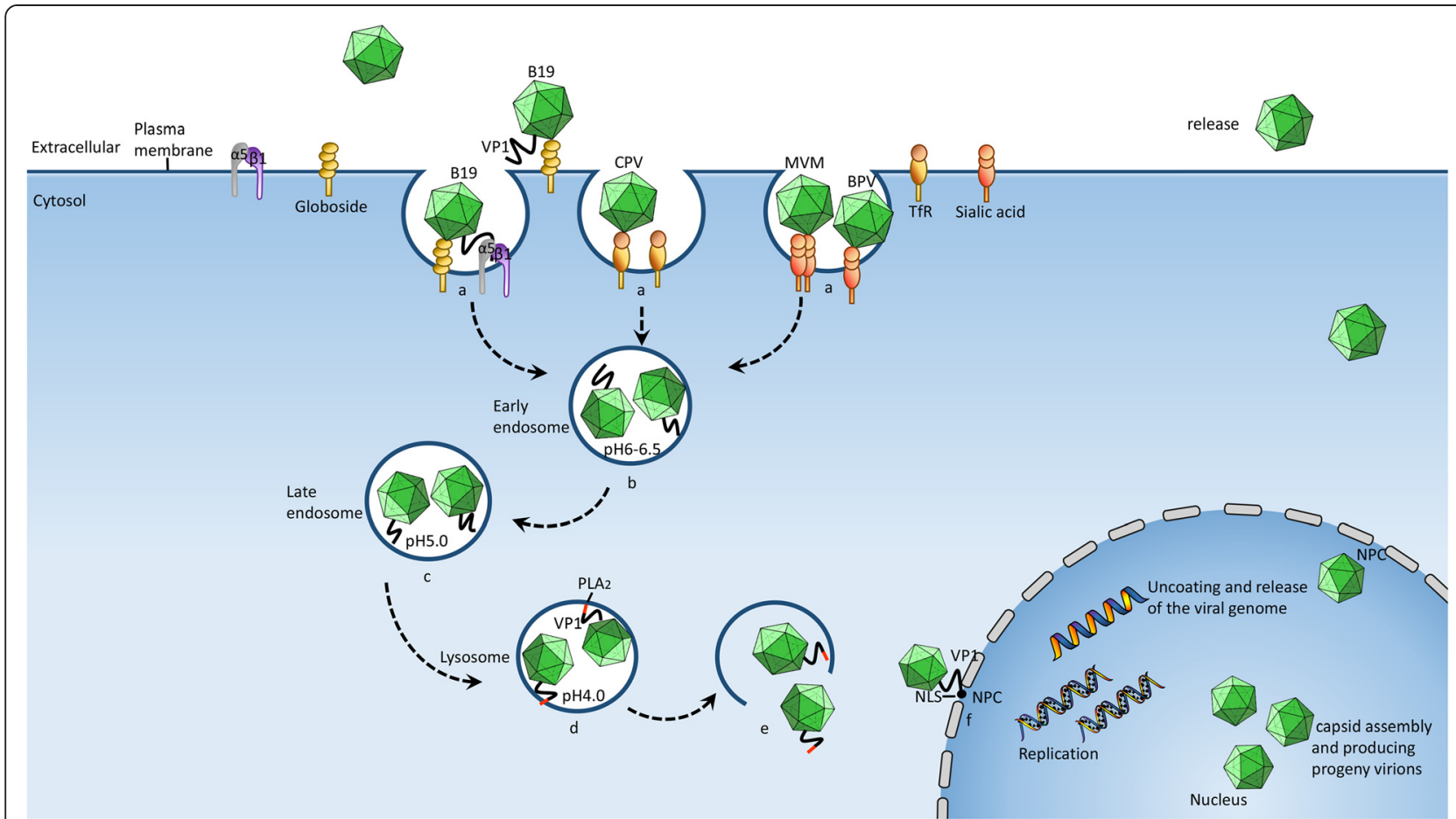

Fig. 1 A schematic of the parvovirus infection process, mediated by the Clathrin-dependent endocytic pathway. The internalization of the virus is mediated by the endocytosis pathway, primarily through the following steps. a Receptor binding-mediated internalization. The cellular receptor for parvovirus B19 is globoside, the cellular receptor for CPV is transferrin receptor (TfR), and the cellular receptor for MVM and BPV is sialic acid. b Form of the early endosome ( $\mathrm{pH}$ 6.0-6.5). c Transformed into the late endosome at lower pH conditions ( $\mathrm{pH}$ 5). $\mathbf{d}$ Transformed into the lysosome and the activation of phospholipase $\mathrm{A}_{2}$ (PLA2) ( $\mathrm{pH}$ 4.0). e The activated PLA2 destroys the integrity of the lysosomal membrane. Thus, the viruses are released into the cytosol. $\mathbf{f}$ The viruses are transported towards the nucleus and target on the karyotheca with the help of the VP1 nuclear localization signal (NLS). The movement of microtubule and actin filaments are involved in the entire process of viral infection, from the early endosome to the peripheral nucleus. The viral genome begins to replicate and assemble after trafficking through the nuclear pore complex (NPC). The matured virions finally move through the NPC and are released extracellular

elements, which contain the NLS, most likely participate in the nuclear transport in other representative parvoviruses, as well. A recent study showed that the PPV was distinctly different from the closely related parvoviruses because the PPV had more than one activated NLS, including a novel nuclear localization motif (NLM) [42]. One of the NLSs is typically located on the VP1 Nterminal and plays a role in the early steps of infection, whereas the other NLS is a novel NLM that targets the VP2 trimers to the nucleus late in the infection [42]. Additionally, in the genus Bocaparvovirus, the NLSs display some distinct properties in comparison with the other parvoviruses. Direct experiments suggest that the human bocavirus NP1 protein possesses a nonconventional NLS and is capable of transporting $\beta$-galactosidase fusion proteins to the nucleus [43], which indicates that the NP1 plays a role in nuclear translocation. Notably, in ADV, the VP1 binds the DNA, and the virus can not replicate efficiently in the nucleus because of the absence of the NLS [44].

In the majority of parvoviruses, the VP1 N-termini have a secretory $\mathrm{PLA}_{2}\left(\mathrm{sPLA}_{2} \mathrm{~s}\right)$ homology domain, which contains the catalytic site of a sPLA $A_{2}$ and a conserved $\mathrm{Ca}^{2+}$ binding loop. However, a few of the viruses do not have this motif. The PLA 2 is a lipolytic enzyme that destroys the membrane and allows the viruses to escape from the lysosome. Additionally, the $\mathrm{PLA}_{2}$ is located initially within the native capsid but is then turned to the outside after heat or $\mathrm{pH}$ treatments [34]. In addition to the conserved amino acids within the VP1u $\mathrm{PLA}_{2}$ motif, some nonconserved amino acid residues around the VP1u also have an effect on PLA $\mathrm{P}_{2}$ activity. The $\mathrm{B} 19$ mutants of the PLA $\mathrm{P}_{2}$ motif showed a significant decrease in PLA $\mathrm{A}_{2}$ activity and viral infectivity, which suggested that the $\mathrm{PLA}_{2}$ played an important role in the B19 life cycle [45]. Furthermore, in their study, Deng et al. demonstrated that the integrity of the cell membrane was destroyed by PLA $A_{2}$ in a B19 infection. When the UT7-Epo cells were incubated with purified VP1u proteins, the cell morphology changed with time until finally the change was abrupt, resulting even in death, with an increase in the VP1u treatment. However, in comparison, the cells with mutant VP1u proteins or those in the control treatment did not change [46]. The identical effect was also 
validated for the AAV [47]. Additionally, the structural and conformational changes that occurred during the VP1 $\mathrm{N}$-terminal externalization from the inner capsid to the outside were physically revealed [48]. In a comparison with humans, the question remains whether the same process occurs in animals. In the MVM, the phosphorylation of $\mathrm{PLA}_{2}$ activity also influenced the stage of virus released from the endosome. After A9 cells were transfected with VP1u mutant infectious clones, the PLA $A_{2}$ activity and the MVM infectivity were both abrogated [49]. Similarly in CPVs, when the capsid was incubated with $\mathrm{PLA}_{2}$ inhibitors, the infectivity of the CPVs was significantly reduced and the endosome membrane permeability was changed during the period of CPV infection [35]. These results also demonstrated that $\mathrm{PLA}_{2}$ activity is essential for effective infection.

\section{VP2 participates in the receptor recognition and in nuclear translocation}

Viral infection begins with the adhesion of the virus to a cell surface receptor [50]. In viruses, there is also an "anti-receptor" that is found in the parvovirus VP2 protein, which attaches to the cell receptor and begins internalization (Table 1). With the use of the cryo-electron microscopy technique at the resolution of 8 - $\AA$, a depression at the icosahedral threefold axes of the B19 VP2 capsid was found, which bound to the cellular receptor globoside [51]. In the AAV-2, the heparin sulphate proteoglycan is a dominant receptor [52], which shares a common receptor $\alpha 5 \beta 1$ with $\mathrm{B} 19$. When the AAV-2 was combined with heparin, at $\sim 18 \AA$ resolution under cryoelectron microscopy, the conformational changes of the capsid were revealed; the tip of the protrusions on the three-fold axes became flat, and the top of the channel located on top of the five-fold axes grew broader [53]. In contrast to B19, there is a distinct "spike" on the threefold axes of CPV VP2, based on observations of the 3D structure. On the VP2 capsid surface, there is a putative receptor-binding region located in a depression with a canyon-like shape. Moreover, one of the binding regions is located between the two icosahedral three-fold axes, and the other binding region is on the five-fold axes [30]. The BPV capsid VP2 showed a common parvovirus feature, obvious protrusions encircling the threefold axes, which indicated a potential site for receptor recognition [9]. For ADV, the 3D structure of VP2 capsid have been determined to $22 \AA$ resolution, a dimple at the twofold axes was indicated to be involed in the recognition of cellular receptor [31].

Notably, a new NLS of the B19 virus was located on the VP2 N-terminal, which could facilitate nuclear transport [54]. In the case of MVM, the VP2 N-terminal also acted as a nuclear export signal (NES) [55]. In further studies, when the temperature reached a specific level, the VP2 N-terminal region of the MVM transferred from the inner capsid through the five-fold axes to the outside of the virion [56]. After a series of conformational changes and the exposure of the NLS and NLM, the VP1 cooperated with the VP2 and formed a trimer with the assistance of VP2-chaperone activity to finally traffic through the nuclear pore complex [57]. Additionally, the VP2 N-terminal was phosphorylated during the late stage of the MVM life cycle, and therefore, the viruses spread to neighbouring cells efficiently prompted by the activated VP2. Miller et al. hypothesised that the N-terminal of the VP2 together with the NS2 had an influence on the viral egress from the nucleus [58]. In the case of ADV, a D534 residue of the VP2 enabled the ADV-G to replicate in mink, which induced a continuous immune response [59].

\section{VP3 function as a capsid scaffold?}

The VP3 generally occurs only when the viral genome has completed the capsid assembly and packaging. In the MVM, the VP3 is generated from the cleavage of VP2 at approximately 25 amino acids from the $\mathrm{N}$ terminal. A trypsin digestion experiment demonstrated that this proteolytic reaction occurred only in the mature virion, with an intact genome. Although the VP1 has an identical proteolytic site, cleavage does not occur [60]. An identical proteolytic phenomenon also appeared in the ADV, but with some dissimilarity. Previous studies showed that during an ADV infection or when the viral capsid only was expressed an extra, an unknown $26 \mathrm{kDa}$ protein was produced, which was recently identified as a split product of the capsid VP1 and VP2. Based on the results, the caspase family was activated during the expression of the ADV capsid proteins, and the caspase- 7 response was to specifically cleavage the capsid at a distinct site [61].

The studies on VP1 and VP2 are sufficiently comprehensive, but research on VP3 is lacking, and further studies are required to reveal the discrete functions of this protein. For birds, the VP3 is a prominent protein in both GPV and Muscovy duck parvovirus (MDPV), in which the VP3 induced a distinct immune response [62]. Recombinant GPV capsid proteins were expressed and purified to apply to an in vivo assay, and all of the VLPs induced a strong immune response in the susceptible geese, whereas the VLPs-VP2 and VLPs-VP3 induced higher concentrations of neutralized antibodies than the VLPs-VP1 [11].

Notably, a $23 \mathrm{kDa}$ protein encoded by the AAV ORF2 promoted the assembly of the VP3 capsid and was named as one of the assembly-activating proteins (AAP). When the AAP was expressed, some of the VP3 was transformed into the nucleus to form the capsid [63], which indicated that the AAP enabled the transport of 
Table 1 The subfamily Parvovirinae: the interaction between the virus and the host

\begin{tabular}{|c|c|c|c|c|c|c|}
\hline Genus & Virus & Host & Cellular Receptor & Invasion pathway & Binding site & $\begin{array}{l}\text { Accession } \\
\text { number }\end{array}$ \\
\hline Amdoparvovirus & $\begin{array}{l}\text { Aleutian mink disease } \\
\text { virus }\end{array}$ & Mink & Sialic acid & - & $\begin{array}{l}\text { A protrusions on threefold axes and } \\
\text { the wall of the dimples on twofold axe }\end{array}$ & M20036 \\
\hline Bocaparvovirus & Bovine parvovirus & Bovine & a2-3 O-linked sialic acid & Clathrin-dependent endocytic pathway & - & M14363 \\
\hline \multirow[t]{2}{*}{ Dependoparvovirus } & $\begin{array}{l}\text { Adeno-associated } \\
\text { virus }\end{array}$ & Human & $\begin{array}{l}\text { Heparan sufate proteoglycan, } \\
\text { sialic acid, aV } \beta 5 \text { integrin }\end{array}$ & $\begin{array}{l}\text { Clathrin-dependent or independent } \\
\text { internalization }\end{array}$ & - & \\
\hline & Goose parvovirus & $\begin{array}{l}\text { Goose, Muscovy } \\
\text { duck }\end{array}$ & - & - & - & U25749 \\
\hline Erythroparvovirus & $\begin{array}{l}\text { Human parvovirus } \\
\text { B19 }\end{array}$ & Human & $P$ antigen, a5 $\beta 1$, ku80 & Clathrin-dependent endocytic pathway & At depression of the three fold axis & NC_000883 \\
\hline \multirow[t]{4}{*}{ Protoparvovirus } & Canine parvovirus & Dogs, cats & Transferrin receptor & Clathrin-dependent endocytic pathway & A distinct "spike" on threefold axes & EF011664 \\
\hline & Minute virus of mice & Rodents & $\begin{array}{l}\text { a2-3 and a2-8 N-linked } \\
\text { Sialic acid }\end{array}$ & $\begin{array}{l}\text { Both clathrin- and lipid-raft mediated } \\
\text { endocytosis }\end{array}$ & $\begin{array}{l}\text { At the depression of twofold axes and } \\
\text { the floor of twofold axes depression }\end{array}$ & V01115 \\
\hline & Porcine parvovirus & Swine & $\begin{array}{l}\text { a2-3 N- and O-linked } \\
\text { Sialic Acid }\end{array}$ & $\begin{array}{l}\text { Macropinocytosis and Clathrin-dependent } \\
\text { endocytic pathway }\end{array}$ & - & M38367 \\
\hline & Mink enteritis virus & Mink & Transferrin receptor & - & - & D00765 \\
\hline
\end{tabular}


VP proteins to the nucleoli and was required for the capsid package. The inference was that the VP3 was responsible for the capsid assembly and the virion stability. However, the role of VP3 in the parvovirus life cycle remains to be fully understood.

\section{Applications of capsid proteins}

For the viral capsid, engineers conducted a variety of innovations. Other viruses, for example, a non-enveloped virus in the Picornavirus family that causes foot-andmouth disease (FMD), have much in common with parvoviruses, and interference against the VP1 structural protein successfully produced a protective effect in both cells and suckling mice [64]. This result indicated that RNAi technology might provide a therapeutic measure to treat virus infection. In the parvoviruses, the dominant antigenic determinants are located on the capsid. Langeveld et al. used an immunofluorescent assay to analyse the B-cell epitopes on structural proteins and, based on this research, obtained the CPV polypeptide vaccine [65]. Moreover, the VLPs-VP2 of the CPV expressed in Escherichia coli and inoculated in mice showed subtle differences between the native viruses and the VLPs in neutralizing antibody titres, in addition to the immune response of the T-cells [66]. The CPV VLPs shared properties closely with the native virus and could be profitable candidates for therapeutic vaccines. Furthermore, researchers used the relation between CPV and its cellular receptor TfR (also exist in human cells) to explore a potential nano-container for tumor targeting. In their study, the accessible lysines on the viral capsid were derivatized with dye molecules. After incubation with TfR expression or those that lacked the TfR expression cell lines, Researchers found that the internalization of the labelled CPV-VLPs was observed only in the TfR expression cell lines [67], which indicated that the CPV-VLPs could act as a target delivery substance.

Adeno-associated viruses (AAVs) are nonpathogenic members of the Parvoviridae family. The last 10 years has witnessed a surge of studies on the use of AAVs as vectors. For example, a recombinant triple-tyrosine mutant AAV-2 vector significantly increased the efficiency of gene transduction, approximately three-fold compared with the wild type [68]. Thus, we could minimize the therapeutic dose and produce a preferred level of protection. More recently, Giridhara et al. found that AAV vectors activated the NF- $\mathrm{KB}$ pathway, which suggested an application in gene therapy [69]. Furthermore, Mirta et al. constructed a recombinant AAV capsid vector, which contained a fragment of a tumour-targeting sequence, and the modified mutant resulted in high transduction in tumour cells, but the transduction in $293 \mathrm{~T}$ cells was poorly induced. By contrast, the native AAV capsid was highly expressed in the $293 \mathrm{~T}$ cell lines, and this altered tropism suggested a strategy to develop an in vivo-targeted vaccine [70].

\section{Conclusions}

Although the size and structure of the parvovirus capsid are simple, each component of the capsid performs a vital function in the life cycle of a virus. The components of the capsid participate in cellular recognition, the endosomal pathway and nuclear trafficking and even induce the immune response. In this review, we summarized the roles of the capsid in viral infection and also the potential applications of recombinant viral capsids in the treatment of disease. In the last several years, studies on the capsids of the parvoviruses have grown in number. Nevertheless, the exact function of the VP3 must be fully elucidated. Recently, many new virus strains were categorized into Parvoviridae after the revision of the family; however, the studies on these strains remain at the bioinformatics analysis stage. In the future, more functional-type research must be developed. Furthermore, the study of virus-host interactions remains a major challenge, and an understanding of the mechanisms of the interplay between the virus and the host will contribute to the development of future treatments. Additionally, the safety of the engineered vaccines requires consideration.

\section{Abbreviations}

PRRs: Pattern recognition receptors; VLP: virus-like particle; NS: Non-structural; VP: Viral particle; B19: Human parvovirus B19; AAV: Adeno-associated viruses; GPV: goose parvovirus; ORF: Open reading frames; ITR: Inverted terminal repeats; MVM: Minute virus of mice; CPV: Canine parvovirus; PPV: Porcine parvovirus; BPV: Bovine parvovirus; NLS: Nuclear localization signal; PLA2: Phospholipase A2; ADV: Aleutian mink disease virus; VP1 U: VP1 Nterminal unique region; NLM: Nuclear localization motif; NPC: Nuclear pore complex.

\section{Competing interests}

The authors declare that they have no competing interests.

\section{Authors' contributions}

MT and FL developed the structural design of the review and drafted the manuscript. SC, MW and AC were involved in revising the manuscript critically for important intellectual content. All authors read and approved the final manuscript.

\section{Acknowledgements}

This work was funded by National Natural Science Foundation of China (31201891), Sichuan Provincial Cultivation Program for Leaders of Disciplines in Science (2012JQ0040), Major Project of Education Department in Sichuan Province (12ZA107), Specialized Research Fund for the Doctoral Program of Higher Education (No. 20125103120012), Innovative Research Team Program in Education Department of Sichuan Province (No.12TD005, 2013TD0015), National Science and Technology support program (No. 2015BAD12B05); National Special Fund for Agro-scientific Research in the Public Interest (No. 201003012, and China Agricultural Research System (CARS-43-8).

\section{Author details}

${ }^{1}$ Institute of Preventive Veterinary Medicine, Sichuan Agricultural University, Wenjiang District, Chengdu City, Sichuan Province 611130, China. ${ }^{2}$ Avian Disease Research Center, College of Veterinary Medicine of Sichuan Agricultural University, Wenjiang District, Chengdu City, Sichuan Province 611130, China. ${ }^{3}$ Key Laboratory of Animal Disease and Human Health of 
Sichuan Province, Sichuan Agricultural University, Wenjiang District, Chengdu City, Sichuan Province 611130, China.

\section{Received: 7 April 2015 Accepted: 15 July 2015}

\section{Published online: 04 August 2015}

\section{References}

1. Buller RM, Janik JE, Sebring ED, Rose JA. Herpes simplex virus types 1 and 2 completely help adenovirus-associated virus replication. J Virol. 1981;40(1):241-7.

2. Geoffroy MC, Salvetti A. Helper functions required for wild type and recombinant adeno-associated virus growth. Curr Gene Ther. 2005;5(3):265-71.

3. Cotmore SF, Agbandje-McKenna M, Chiorini JA, Mukha DV, Pintel DJ, Qiu J, et al. The family Parvoviridae. Arch Virol. 2014;159(5):1239-47. doi:10.1007/ s00705-013-1914-1.

4. Lehmann HW, Kuhner L, Beckenlehner K, Muller-Godeffroy E, Heide KG, Kuster RM, et al. Chronic human parvovirus B19 infection in rheumatic disease of childhood and adolescence. J Clin Virol. 2002;25(2):135-43.

5. De Jong EP, de Haan TR, Kroes AC, Beersma MF, Oepkes D, Walther FJ. Parvovirus B19 infection in pregnancy. J Clin Virol. 2006;36(1):1-7. doi:10.1016/j.jcv.2006.01.004.

6. Gao G, Vandenberghe LH, Alvira MR, Lu Y, Calcedo R, Zhou X, et al. Clades of Adeno-associated viruses are widely disseminated in human tissues. J Virol. 2004;78(12):6381-8. doi:10.1128/JVI.78.12.6381-6388.2004.

7. Decaro N, Buonavoglia C. Canine parvovirus - a review of epidemiological and diagnostic aspects, with emphasis on type 2c. Vet Microbiol. 2012;155(1):1-12

8. Brown KE, Green SW, Young NS. Goose parvovirus - an autonomous member of the dependovirus genus? Virology. 1995;210(2):283-91.

9. Kailasan S, Halder S, Gurda B, Bladek H, Chipman PR, McKenna R, et al. Structure of an enteric pathogen, bovine parvovirus. J Virol. 2015;89(5):2603-14. doi:10.1128/JVI.03157-14

10. Antonis AF, Bruschke CJ, Rueda P, Maranga L, Casal Jl, Vela C, et al. A novel recombinant virus-like particle vaccine for prevention of porcine parvovirusinduced reproductive failure. Vaccine. 2006;24(26):5481-90. doi:10.1016.

11. Ju H, Wei N, Wang Q, Wang C, Jing Z, Guo L, et al. Goose parvovirus structural proteins expressed by recombinant baculoviruses self-assemble into virus-like particles with strong immunogenicity in goose. BBRC. 2011:409(1):131-6.

12. Babkin IV, Tyumentsev Al, Tikunov AY, Zhirakovskaia EV, Netesov SV, Tikunova NV. A study of the human bocavirus replicative genome structures. Virus Res. 2015;195:196-202. doi:10.1016/j.virusres 2014.10.019.

13. Jiang $Y H$, Xiao CT, Yin SH, Gerber PF, Halbur PG, Opriessnig T. High prevalence and genetic diversity of porcine bocaviruses in pigs in the USA and identification of multiple novel porcine bocaviruses. J Gen Virol. 2014;95(Pt 2):453-65. doi:10.1099/vir.0.057042-0.

14. Kapoor A, Mehta N, Dubovi EJ, Simmonds P, Govindasamy L, Medina JL, et al. Characterization of novel canine bocaviruses and their association with respiratory disease. J Gen Virol. 2012;93(Pt 2):341-6. doi:10.1099/vir.0.036624-0.

15. Li L, Shan T, Wang C, Cote C, Kolman J, Onions D, et al. The fecal viral flora of California sea lions. J Virol. 2011;85(19):9909-17. doi:10.1128/JVI.05026-11.

16. Nuesch JP, Rommelaere J. NS1 interaction with CKII alpha: novel protein complex mediating parvovirus-induced cytotoxicity. J Virol. 2006;80(10):4729-39. doi:10.1128/JVI.80.10.4729-4739.2006.

17. Poole BD, Zhou J, Grote A, Schiffenbauer A, Naides SJ. Apoptosis of liver-derived cells induced by parvovirus B19 nonstructural protein. J Virol. 2006:80(8):4114-21. doi:10.1128/JVl.80.8.4114-4121.2006.

18. Moffatt S, Tanaka N, Tada K, Nose M, Nakamura M, Muraoka O, et al. A cytotoxic nonstructural protein, NS1, of human parvovirus B19 induces activation of interleukin-6 gene expression. J Virol. 1996;70(12):8485-91.

19. Kaufmann B, Simpson AA, Rossmann MG. The structure of human parvovirus B19. PNAS. 2004;101(32):11628-33.

20. Walters RW, Agbandje-McKenna M, Bowman VD, Moninger TO, Olson NH, Seiler $\mathrm{M}$, et al. Structure of adeno-associated virus serotype 5. J Virol. 2004;78(7):3361-71.

21. Xie Q, Lerch TF, Meyer NL, Chapman MS. Structure-function analysis of receptor-binding in adeno-associated virus serotype 6 (AAV-6). Virology. 2011:420(1):10-9. doi:10.1016/j.virol.2011.08.011.

22. Nam HJ, Lane MD, Padron E, Gurda B, McKenna R, Kohlbrenner E, et al. Structure of adeno-associated virus serotype 8 , a gene therapy vector. J Virol. 2007;81(22):12260-71. doi:10.1128/JVI.01304-07.
23. Padron E, Bowman V, Kaludov N, Govindasamy L, Levy H, Nick P, et al. Structure of adeno-associated virus type 4. J Virol. 2005;79(8):5047-58. doi:10.1128/JVI.79.8.5047-5058.2005.

24. Quesada O, Gurda B, Govindasamy L, McKenna R, Kohlbrenner E, Aslanidi $G$, et al. Production, purification and preliminary X-ray crystallographic studies of adeno-associated virus serotype 7. Acta Crystallogr Sect F: Struct Biol Cryst Commun. 2007;63(Pt 12):1073-6. doi:10.1107/ S1744309107060289.

25. Mitchell M, Nam HJ, Carter A, McCall A, Rence C, Bennett A, et al. Production, purification and preliminary X-ray crystallographic studies of adeno-associated virus serotype 9. Acta Crystallogr Sect F: Struct Biol Cryst Commun. 2009;65(Pt 7):715-8. doi:10.1107/S1744309109021460.

26. Miller EB, Gurda-Whitaker B, Govindasamy L, McKenna R, Zolotukhin S, Muzyczka N, et al. Production, purification and preliminary X-ray crystallographic studies of adeno-associated virus serotype 1. Acta Crystallogr Sect F: Struct Biol Cryst Commun. 2006;62(Pt 12):1271-4. doi:10.1107/S1744309106048184.

27. Xie Q, Bu W, Bhatia S, Hare J, Somasundaram T, Azzi A, et al. The atomic structure of adeno-associated virus (AAV-2), a vector for human gene therapy. PNAS. 2002;99(16):10405-10.

28. Agbandje-McKenna M, Llamas-Saiz AL, Wang F, Tattersall P, Rossmann MG. Functional implications of the structure of the murine parvovirus, minute virus of mice. Structure. 1998;6(11):1369-81.

29. Organtini LJ, Allison AB, Lukk T, Parrish CR, Hafenstein S. Global displacement of canine parvovirus by a host-adapted variant: structural comparison between pandemic viruses with distinct host ranges. J Virol. 2015;89(3):1909-12. doi:10.1128/JVI.02611-14.

30. Tsao J, Chapman MS, Agbandje M, Keller W, Smith K, Wu H, et al. The threedimensional structure of canine parvovirus and its functional implications. Science. 1991;251(5000):1456-64.

31. McKenna R, Olson NH, Chipman PR, Baker TS, Booth TF, Christensen J, et al. Three-dimensional structure of Aleutian mink disease parvovirus: implications for disease pathogenicity. J Virol. 1999;73(8):6882-91.

32. Vihinen-Ranta M, Wang D, Weichert WS, Parrish CR. The VP1 N-terminal sequence of canine parvovirus affects nuclear transport of capsids and efficient cell infection. J Virol. 2002;76(4):1884-91.

33. Mani B, Baltzer C, Valle N, Almendral JM, Kempf C, Ros C. Low pHdependent endosomal processing of the incoming parvovirus minute virus of mice virion leads to externalization of the VP1 N-terminal sequence (N-VP1), N-VP2 cleavage, and uncoating of the full-length genome. J Virol. 2006:80(2):1015-24. doi:10.1128/JVI.80.2.1015-1024.2006.

34. Ros C, Gerber M, Kempf C. Conformational changes in the VP1-unique region of native human parvovirus B19 lead to exposure of internal sequences that play a role in virus neutralization and infectivity. J Virol. 2006;80(24):12017-24.

35. Suikkanen S, Antila M, Jaatinen A, Vihinen-Ranta M, Vuento M. Release of canine parvovirus from endocytic vesicles. Virology. 2003;316(2):267-80.

36. Lombardo E, Ramirez JC, Garcia J, Almendral JM. Complementary roles of multiple nuclear targeting signals in the capsid proteins of the parvovirus minute virus of mice during assembly and onset of infection. J Virol. 2002;76(14):7049-59.

37. Sonntag F, Bleker S, Leuchs B, Fischer R, Kleinschmidt JA. Adeno-associated virus type 2 capsids with externalized VP1/NP2 trafficking domains are generated prior to passage through the cytoplasm and are maintained until uncoating occurs in the nucleus. J Virol. 2006;80(22):11040-54. doi:10.1128/ JVI.01056-06.

38. Quattrocchi S, Ruprecht N, Bonsch C, Bieli S, Zurcher C, Boller K, et al. Characterization of the early steps of human parvovirus B19 infection. J Virol. 2012;86(17):9274-84. doi:10.1128/JVI.01004-12.

39. Bonsch C, Zuercher C, Lieby $P$, Kempf C, Ros $C$. The globoside receptor triggers structural changes in the B19 virus capsid that facilitate virus internalization. J Virol. 2010;84(22):11737-46. doi:10.1128/JVI.01143-10.

40. Leisi R, Ruprecht N, Kempf C, Ros C. Parvovirus B19 Uptake Is a Highly Selective Process Controlled by VP1u, a Novel Determinant of Viral Tropism. J Virol. 2013;87(24):13161-7.

41. Vihinen-Ranta M, Kakkola L, Kalela A, Vilja P, Vuento M. Characterization of a nuclear localization signal of canine parvovirus capsid proteins. Eur J Biochem. 1997;250(2):389-94.

42. Boisvert M, Bouchard-Levesque V, Fernandes S, Tijssen P. Classic nuclear localization signals and a novel nuclear localization motif are required for 
nuclear transport of porcine parvovirus capsid proteins. J Virol. 2014;88(20):11748-59. doi:10.1128/JVI.01717-14.

43. Li Q, Zhang Z, Zheng Z, Ke X, Luo H, Hu Q, et al. Identification and characterization of complex dual nuclear localization signals in human bocavirus NP1. J Gen Virol. 2013;94(Pt 6):1335-42. doi:10.1099/vir.0.047530-0.

44. Willwand K, Kaaden O-R. Capsid protein VP1 (p85) of Aleutian disease virus is a major DNA-binding protein. Virology. 1988;166(1):52-7.

45. Zadori Z, Szelei J, Lacoste MC, Li Y, Gariepy S, Raymond P, et al. A viral phospholipase A2 is required for parvovirus infectivity. Dev Cell. 2001;1(2):291-302.

46. Deng $X$, Dong $Y$, Yi Q, Huang $Y$, Zhao D, Yang $Y$, et al. The determinants for the enzyme activity of human parvovirus B19 phospholipase A2 (PLA2) and its influence on cultured cells. PLoS One. 2013;8(4), e61440. doi:10.1371/ journal.pone.0061440.

47. Stahnke S, Lux K, Uhrig S, Kreppel F, Hösel M, Coutelle O, et al. Intrinsic phospholipase A2 activity of adeno-associated virus is involved in endosomal escape of incoming particles. Virology. 2011;409(1):77-83.

48. Venkatakrishnan B, Yarbrough J, Domsic J, Bennett A, Bothner B, Kozyreva $\mathrm{OG}$, et al. Structure and dynamics of adeno-associated virus serotype 1 VP1unique N-terminal domain and its role in capsid trafficking. J Virol. 2013;87(9):4974-84. doi:10.1128/JVI.02524-12.

49. Farr GA, Zhang LG, Tattersall P. Parvoviral virions deploy a capsid-tethered lipolytic enzyme to breach the endosomal membrane during cell entry. PNAS. 2005;102(47):17148-53.

50. Smith AE, Helenius A. How viruses enter animal cells. Science. 2004;304(5668):237-42.

51. Chipman PR, Agbandje-McKenna M, Kajigaya S, Brown KE, Young NS, Baker TS, et al. Cryo-electron microscopy studies of empty capsids of human parvovirus B19 complexed with its cellular receptor. PNAS. 1996;93(15):7502-6.

52. Summerford C, Samulski RJ. Membrane-associated heparan sulfate proteoglycan is a receptor for adeno-associated virus type 2 virions. J Virol. 1998;72(2):1438-45.

53. Levy HC, Bowman VD, Govindasamy L, McKenna R, Nash K, Warrington K, et al. Heparin binding induces conformational changes in Adeno-associated virus serotype 2. J Struct Biol. 2009;165(3):146-56. doi:10.1016/ j.jsb.2008.12.002.

54. Pillet S, Annan Z, Fichelson S, Morinet F. Identification of a nonconventional motif necessary for the nuclear import of the human parvovirus B19 major capsid protein (VP2). Virology. 2003:306(1):25-32.

55. Sánchez-Martínez C, Grueso E, Carroll M, Rommelaere J, Almendral JM. Essential role of the unordered VP2 n-terminal domain of the parvovirus MVM capsid in nuclear assembly and endosomal enlargement of the virion fivefold channel for cell entry. Virology. 2012:432(1):45-56.

56. Maroto B, Valle N, Saffrich R, Almendral JM. Nuclear export of the nonenveloped parvovirus virion is directed by an unordered protein signal exposed on the capsid surface. J Virol. 2004;78(19):10685-94. doi:10.1128/ JVI.78.19.10685-10694.2004

57. Lombardo E, Ramirez JC, Agbandje-McKenna M, Almendral JM. A betastranded motif drives capsid protein oligomers of the parvovirus minute virus of mice into the nucleus for viral assembly. J Virol. 2000;74(8):3804-14.

58. Miller CL, Pintel DJ. Interaction between parvovirus NS2 protein and nuclear export factor $\mathrm{Crm} 1$ is important for viral egress from the nucleus of murine cells. J Virol. 2002;76(7):3257-66.

59. Fox JM, McCrackin Stevenson MA, Bloom ME. Replication of Aleutian mink disease parvovirus in vivo is influenced by residues in the VP2 protein. J Virol. 1999;73(10):8713-9.

60. Weichert WS, Parker JS, Wahid AT, Chang SF, Meier E, Parrish CR. Assaying for structural variation in the parvovirus capsid and its role in infection. Virology. 1998;250(1):106-17. doi:10.1006/viro.1998.9352.

61. Cheng F, Chen AY, Best SM, Bloom ME, Pintel D, Qiu J. The capsid proteins of Aleutian mink disease virus activate caspases and are specifically cleaved during infection. J Virol. 2010;84(6):2687-96. doi:10.1128/JVI.01917-09.

62. Le Gall-Reculé G, Jestin V, Chagnaud P, Blanchard P, Jestin A. Expression of muscovy duck parvovirus capsid proteins (VP2 and VP3) in a baculovirus expression system and demonstration of immunity induced by the recombinant proteins. J Virol. 1996;77(9):2159-63.

63. Sonntag F, Schmidt K, Kleinschmidt JA. A viral assembly factor promotes AAV2 capsid formation in the nucleolus. PNAS. 2010;107(22):10220-5.

64. Chen W, Yan W, Du Q, Fei L, Liu M, Ni Z, et al. RNA interference targeting VP1 inhibits foot-and-mouth disease virus replication in BHK-21 cells and suckling mice. J Virol. 2004;78(13):6900-7. doi:10.1128/JVI.78.13.69006907.2004.

65. Langeveld JP, Casal JI, Vela C, Dalsgaard K, Smale SH, Puijk WC, et al. B-cell epitopes of canine parvovirus: distribution on the primary structure and exposure on the viral surface. J Virol. 1993;67(2):765-72.

66. Xu J, Guo HC, Wei YQ, Dong H, Han SC, Ao D, et al. Self-assembly of viruslike particles of canine parvovirus capsid protein expressed from Escherichia coli and application as virus-like particle vaccine. Appl microbiol biot. 2014;98(8):3529-38. doi:10.1007/s00253-013-5485-6.

67. Singh P, Destito G, Schneemann A, Manchester M. Canine parvovirus-like particles, a novel nanomaterial for tumor targeting. J Nanobiotechnology. 2006;4:2. doi:10.1186/1477-3155-4-2.

68. Wang Z, Ma HI, Li J, Sun L, Zhang J, Xiao X. Rapid and highly efficient transduction by double-stranded adeno-associated virus vectors in vitro and in vivo. Gene Ther. 2003;10(26):2105-11. doi:10.1038/sj.gt.3302133.

69. Jayandharan GR, Aslanidi G, Martino AT, Jahn SC, Perrin GQ, Herzog RW, et al. Activation of the NF-kappaB pathway by adeno-associated virus (AAV) vectors and its implications in immune response and gene therapy. PNAS. 2011;108(9):3743-8.

70. Grifman M, Trepel M, Speece P, Gilbert LB, Arap W, Pasqualini R, et al. Incorporation of tumor-targeting peptides into recombinant adenoassociated virus capsids. Mol Ther. 2001;3(6):964-75.

\section{Submit your next manuscript to BioMed Central and take full advantage of:}

- Convenient online submission

- Thorough peer review

- No space constraints or color figure charges

- Immediate publication on acceptance

- Inclusion in PubMed, CAS, Scopus and Google Scholar

- Research which is freely available for redistribution 